\title{
Zolo, Danilo. 2007. La justicia de los vencedores. De Nuremberg a Bagdad. Buenos Aires: Editorial EDHASA, 205 pp.
}

\author{
JULIETA MIRA \\ julieta_mira@yahoo.com.ar
}

lo largo de toda su obra, Danilo Zolo (Rijeka, 1936) ha reflexionado
sobre la democracia, la paz, la guerra y la justicia. El último libro de este
profesor de Filosofía del Derecho de la Universidad de Florencia (Italia) se titula Justicia de los vencedores. De Nuremberg a Bagdad. Fue publicado en italiano en el año 2006 y editado en Buenos Aires en el año 2007; él continúa aquí su contribución iniciada con I signori della pace. Una critica del globalismo giuridico (1998, trad. cast., 2005) y Chi dice umanità. Guerra, diritto e ordine globale (2000). En estos trabajos Zolo realiza un análisis crítico sobre la justicia penal internacional compilando un conjunto de artículos y ensayos escritos en diferentes momentos de su trayectoria.

El autor debate en siete capítulos en torno al valor del "internacionalismo judicial" (2007: 38) adoptando una perspectiva realista de las relaciones internacionales. También indaga sobre el impacto de la justicia internacional en tanto forma preventiva de futuras violaciones de los derechos humanos y camino a la paz mundial. Zolo centra su análisis en las experiencias de los Tribunales Militares de Nuremberg (1945) y Tokio (1946), el Tribunal ad hoc para la Antigua Yugoslavia (1993) y el Iraqi Special Tribunal (2003). También le confiere especial atención al caso paradigmático de Kosovo.

Una de las tesis centrales del libro se construye a partir de la máxima del juez hindú Radhabinod Pal del Tribunal de Tokio: "Sólo la guerra perdida es un crimen internacional" (2007: 54). En contrapunto, los vencedores suelen quedar impunes de los crímenes que hayan cometido, como fue el caso de los bombardeos atómicos de Hiroshima y Nagasaki de agosto de 1945. La otra tesis, que da lugar al mismo título del libro y que representa la otra cara de la moneda con respecto a la tesis anterior, sostiene que la justicia internacional responde a los intereses de los victoriosos de los conflictos armados o de las fuerzas ocupantes, generalmente las grandes potencias.

En la introducción de su libro Zolo declara que se propone denunciar el "sistema dualista" de la justicia internacional (2007: 18). También afirma que existe una "justicia de los vencedores", la cual:

se aplica a los derrotados, a los débiles y a los pueblos oprimidos, con la connivencia de las instituciones internacionales, el silencio encubridor de gran parte de los juristas académicos, la complicidad de los medios masivos de 
comunicación y el oportunismo de [...] las llamadas 'organizaciones no gubernamentales' (2007: 18).

Según el autor, tanto las Naciones Unidas como las Cortes Penales Internacionales no han logrado garantizar la paz ni contener el uso de la maquinaria militar por parte de las potencias. En ese marco, en el primer capítulo afirma que el ordenamiento internacional demuestra su incapacidad de limitar y regular el poder destructivo de la guerra. Al mismo tiempo, Zolo expone su profunda duda acerca de la eficacia de la justicia penal internacional en la prevención de la guerra, y remarca el deslizamiento discursivo de la guerra moderna hacia otro tipo que denomina "guerra global humanitaria".

En el segundo capítulo Zolo comienza analizando los aspectos que legitiman al "militarismo humanitario" (2007: 82) del cual se ha investido Estados Unidos", planteando el fracaso del "pacifismo jurídico" en la consecución de la paz y la protección de los derechos fundamentales que había sido propugnado por Immanuel Kant, Hans Kelsen, Norberto Bobbio y Jürgen Habermas (2007: 82). En el tercer capítulo, Universalidad de los derechos y guerra humanitaria, Zolo cuestiona algunas de las ideas contenidas en Tanner Lectures ${ }^{1}$ que Michael Ignatieff dictó durante el año 2000. Los puntos más conflictivos que Zolo rebate son: el uso de la fuerza militar con fines humanitarios; la apología de las guerras de agresión emprendidas por Estados Unidos y sus aliados europeos; y el "olvido de que la guerra moderna es la negación más radical de los derechos de los individuos" (2007: 102). En el cuarto capítulo el autor se adentra en la descripción de La guerra global preventiva en tanto la sucesora de la guerra moderna luego de la finalización de la "guerra fría" y la caída del "orden bipolar". Se trata de una guerra de orden "preventivo" y con un alcance global, que se orienta hacia objetivos como la seguridad global y el nuevo orden mundial. El autor es categórico al afirmar que se trata de guerras ilegales y terroristas.

El quinto capítulo explora los usos de la noción de "imperio". Zolo concluye que Estados Unidos posee un poder imperial en un sentido complejo, tanto estratégico como normativo (2007: 142). Un poder imperial por fuera y encima del derecho internacional. Es así como la potencia imperial se ha cristalizado en una "policía internacional" (2007: 143) que justifica su acción con argumentos teológicos y éticos. De este modo, Zolo ironiza al poner al descubierto que "la guerra global tiene como fin último promover la paz global” (2007: 144). El capítulo sexto aborda Las razones del terrorismo. También plantea las tensiones entre la denominación de "terrorista" y otras posibles como "combatientes por la libertad" o partisanos. Luego da cuenta de la imposibilidad de que la calificación de "terrorista" le competa a los Estados. Para Zolo la fuente principal del terrorismo internacional se encuentra en el poder avasallador de los occidentales.

1 Publicadas en Ignatieff, Human Rights as Politics and Idolatry, Princeton, Princeton University Press, 2001. 
El capítulo final titulado De Nuremberg a Bagdad es, sin dudas, el eje temático del libro de Zolo. En esas páginas se propone un recorrido histórico de la justicia penal internacional y establece su origen en los Tribunales de Nuremberg y Tokio que, por ende, dieron lugar a una matriz o modelo que el autor sintetiza con la expresión de "justicia de los vencedores". En consecuencia, Zolo plantea tres preguntas nodales que atraviesan el conjunto de la obra: la primera es "¿puede considerarse al proceso de Nuremberg como un modelo a seguir?” (2007: 168). En virtud a la persecución penal internacional se cuestiona: “¿qué finalidad debe atribuirse a la sanción penal internacional?" (2007: 168). Por último: "¿la pena debe concurrir a reparar el daño específico o, en cambio, debe cumplir una función de prevención general del crimen internacional y, en última instancia, de la guerra?" (2007: 168).

Zolo responde que el "modelo de Nuremberg" debería ser desterrado. Con respecto a la sanción y la pena de la justicia internacional, sostiene que se sustenta en el paradigma retributivo, es decir, aquel por el cual el castigo debe ser proporcional al delito cometido. Siguiendo esta línea argumentativa, el autor define a esta justicia como perteneciente al orden sacrificial y vengativo, tendiente a generar un ritual de degradación del acusado que termina reafirmando los valores sociales. Con esta lógica Zolo analiza diversos casos de tribunales internacionales, critica aspectos técnico-jurídicos de los mismos que implicarían una violación del Rule of law y, a su vez, pone en duda su autonomía e imparcialidad, ya sea en Nuremberg, Tokio, La Haya o Irak. A su vez, analiza el Estatuto de Roma que creó en 1998 la Corte Penal Internacional. Según el autor, a través de la creación de dicha instancia los países poderosos lograron formas de control sobre la juridicidad internacional permaneciendo inmunes a cualquier alcance de la justicia sobre su práctica de la guerra.

Asimismo, el autor introduce la necesidad de revisar la "calidad de la justicia" y la "calidad de la pena" (2007: 172) de los tribunales penales internacionales. Esta acción es posible desde tres dimensiones clave: la necesidad de sancionar penalmente a los responsables de graves crímenes internacionales; el carácter ejemplar de las penas; y su función retributiva. Su planteo nodal remite a que estas experiencias no han revertido la impunidad en forma sustantiva ni han sido útiles para prevenir otros hechos de violencia. Por todo aquello comparte con la sociología penitenciaria moderna que el argumento que este modelo de justicia es expresión tanto de un "optimismo penal" (2007: 176) como de un "fetichismo penal y penitenciario" (2007: 177); en otras palabras, considera inviable la creencia en la persecución penal como la vía para la paz y la justicia internacional. Para finalizar, Zolo expresa con contundencia su preocupación ante la nueva guerra global y el poder destructivo de las potencias hegemónicas. El autor deja asentada su clara postura escéptica sobre la historia y la marcha de la experiencia judicial penal internacional.

Con este libro Zolo contribuye al debate sobre la eficacia de la justicia penal internacional, un debate que presupone y no se ocupa de explicitar ya sea en sus términos o en referencia a su estado actual. De todos modos, el autor asume 
| Zolo, Danilo. 2007. La justicia de los vencedores de Nuremberg a Bagdaf...

una posición provocadora y polémica que deja al desnudo el poder que atraviesa al sistema penal internacional. Sin dudas, el dilema que implica la justicia internacional como respuesta a la impunidad de crímenes internacionales queda irresuelto. En consecuencia, por un lado existe consenso en sostener que hasta el momento las experiencias de justicia internacional han sido parciales y limitadas. Por otro, es importante recordar que ante crímenes aberrantes son las propias víctimas y los pueblos, muchas veces, quienes reclaman justicia tanto en el fuero interno como en el internacional. 